OPEN ACCESS

Edited by:

Pietro Celi,

Adisseo, France

Reviewed by:

Yuheng Luo,

Sichuan Agricultural University, China

Nadia Everaert,

University of Liège, Belgium

*Correspondence:

Martin Beaumont

martin.beaumont@inrae.fr

Specialty section:

This article was submitted to Animal Nutrition and Metabolism,

a section of the journal

Frontiers in Veterinary Science

Received: 03 February 2021 Accepted: 20 April 2021

Published: 25 May 2021

Citation:

Chalvon-Demersay T, Luise D, Le Floc'h N, Tesseraud S, Lambert W, Bosi P, Trevisi P, Beaumont $M$ and Corrent E (2021) Functional Amino

Acids in Pigs and Chickens: Implication for Gut Health.

Front. Vet. Sci. 8:663727.

doi: 10.3389/fvets.2021.663727

\section{Functional Amino Acids in Pigs and Chickens: Implication for Gut Health}

\author{
Tristan Chalvon-Demersay ${ }^{1}$, Diana Luise ${ }^{2}$, Nathalie Le Floc' ${ }^{3}$, Sophie Tesseraud ${ }^{4}$, \\ William Lambert ${ }^{1}$, Paolo Bosi ${ }^{2}$, Paolo Trevisi ${ }^{2}$, Martin Beaumont ${ }^{5 *}$ and Etienne Corrent ${ }^{1}$ \\ ${ }^{1}$ METEX NOOVISTAGO, Paris, France, ${ }^{2}$ Department of Agricultural and Food Sciences, University of Bologna, Bologna, Italy, \\ ${ }^{3}$ PEGASE, INRAE, Institut Agro, Saint Gilles, France, ${ }^{4}$ INRAE, Université de Tours, BOA, Nouzilly, France, ${ }^{5}$ GenPhySE, \\ Université De Toulouse, INRAE, ENVT, Toulouse, France
}

In pigs and broiler chickens, the gastrointestinal tract or gut is subjected to many challenges which alter performance, animal health, welfare and livability. Preventive strategies are needed to mitigate the impacts of these challenges on gut health while reducing the need to use antimicrobials. In the first part of the review, we propose a common definition of gut health for pig and chickens relying on four pillars, which correspond to the main functions of the digestive tract: (i) epithelial barrier and digestion, (ii) immune fitness, (iii) microbiota balance and (iv) oxidative stress homeostasis. For each pillar, we describe the most commonly associated indicators. In the second part of the review, we present the potential of functional amino acid supplementation to preserve and improve gut health in piglets and chickens. We highlight that amino acid supplementation strategies, based on their roles as precursors of energy and functional molecules, as signaling molecules and as microbiota modulators can positively contribute to gut health by supporting or restoring its four intertwined pillars. Additional work is still needed in order to determine the effective dose of supplementation and mode of administration that ensure the full benefits of amino acids. For this purpose, synergy between amino acids, effects of amino acid-derived metabolites and differences in the metabolic fate between free and protein-bound amino acids are research topics that need to be furtherly investigated.

Keywords: functional amino acids, oxidative stress, immunity, epithelial barrier, gut microbiota, weaning, coccidiosis

\section{INTRODUCTION}

The main functions of the gut are to ingest, digest, and absorb nutrients to support animal growth and physiological functions while protecting the organism against luminal harmful compounds (toxins, microorganisms, dietary antigens, etc.) (1). This dual function as a filter and a rampart explains the complexity of the organization of the digestive mucosa that is covered by a single layer of epithelial cells. The intestinal epithelium is constantly renewed by cell turnover mediated by stem cells located at the bottom of the crypts. During the migration along the crypt-villus axis, epithelial cells differentiate into absorptive (enterocytes) or secretory (goblet, paneth, enteroendocrine cells) lineages. This cellular complexity supports the two main functions of the intestinal epithelium: nutrition (e.g., secretion of digestive enzyme, nutrient absorption, hormone secretion) and barrier function (e.g., formation of tight junctions, secretion of antimicrobial peptides and mucus). Epithelial cells also communicate with immune cells located in the lamina propria that constitute 
a key component of the defensive system of the digestive mucosa, notably through the secretion of immunoglobulins. This complex organization of the digestive mucosa allows the establishment of a symbiotic relationship with the microbiota that colonizes the gut lumen. This consortium of bacteria, yeasts and protozoa collectively provide benefits to their animal host (2) notably through complex carbohydrate digestion, immune system tuning, and pathogens fighting $(3,4)$.

In livestock, both pigs and chickens are particularly subjected to digestive disturbances especially during the early life because of the immaturity of their digestive tract. Antimicrobial molecules have been massively used to control digestive diseases but increasing concerns on antibioresistance and environmental issues have urged to find non-antimicrobial disease control strategies. During the last decade, there was a significant reduction in the use of antimicrobial but further strategies are needed to maintain or improve the gut health status of pigs and poultry.

Amino acids (AA) are major energy substrates in the intestinal mucosa, limiting constituents of key proteins of the gut barrier and they can regulate immune responses and oxidative stress (5). In this context, the aim of the present review is to summarize the potential of functional AA supplementation to preserve and restore gut health of pigs and chickens. Topic on which a large number of studies is available for both species. The first requirement to evaluate the effects of $\mathrm{AA}$ is a clear definition of gut health that could be applied to pigs and chickens and of its indicators (6) similarly to what has been done in humans (7). In line with the definition of gut health provided by Kogut and Arsenault (6) and Pluske et al. (1, 6), we consider that gut health provides resistance and resilience of the animals to respond and adapt to the challenges that they can encounter, allowing optimal performance, low mortality and morbidity and good overall health. According to our definition, gut health is characterized by four interconnected pillars: (1) epithelial barrier function and absorption (2) intestinal immune fitness (3) oxidative stress homeostasis and (4) microbiota balance as presented in Figure 1. Herein, we first detail the key components of these pillars and define related indicators in pigs and chickens. Then, we review the effects of dietary AA supplementation on gut health indicators providing, when available, a description of the potential mode of actions. Finally, we propose future directions of research to optimize the use of AA supplementation to ameliorate gut health in pigs and chickens.

\section{THE FOUR PILLARS OF GUT HEALTH AND ASSOCIATED INDICATOR}

Pigs and chickens differ in terms of intestinal physiology and organization. To be able to generalize our definition of gut health to both species, we focus in this part on markers and indicators that are considered valid for both pigs and chickens.

\section{Epithelial Barrier, Digestion, and Nutrient Absorption}

Function of digestion and absorption of the nutrients is realized through the coordinated actions of digestive enzymes and

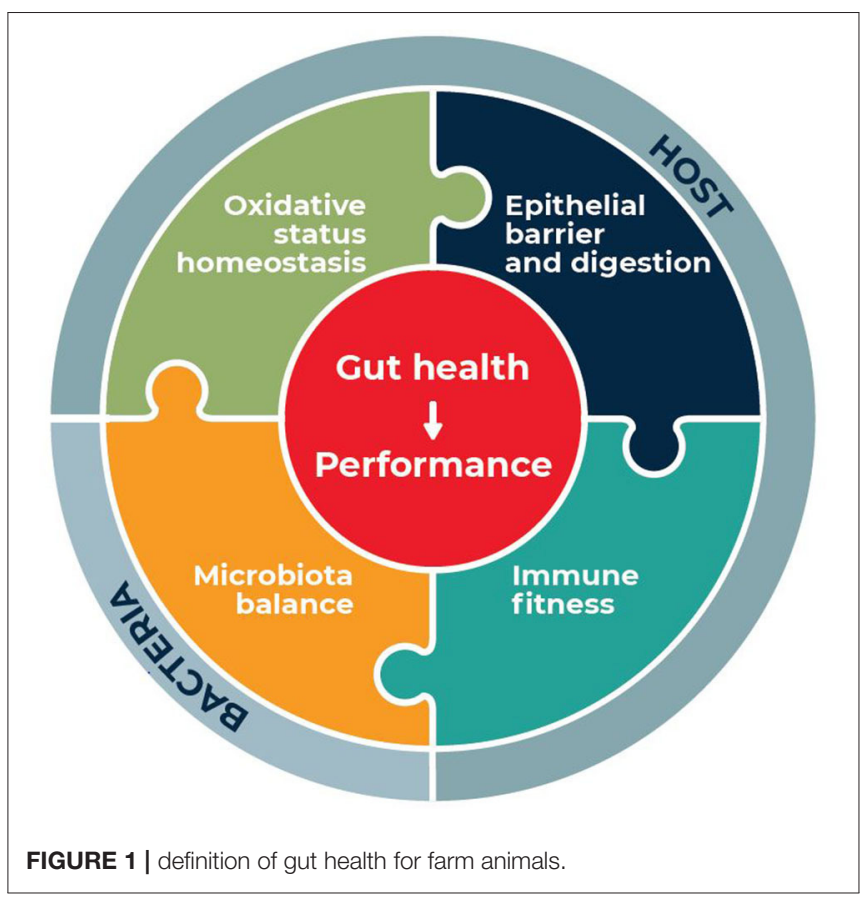

nutrient transporters. These digestion and absorption processes are directly related to the surface of the epithelium. This surface is a function of the height of the villus and the ratio between villus height and crypt depth which are key indicators of absorptive capacity and performance (8). Even a slight villus atrophy due to distress or illness can induce a consequent reduction of the digestive capacity by a reduction of the enzyme secretion from the apical part of the villi (9).

The mucus layer overlying the monolayer of intestinal epithelial cells is the first physical barrier of the gut. This mucus forms a gel and is composed by mucins which are glycoproteins secreted by goblet cells. It prevents the direct contact of toxins and pathogens with the epithelium (10). The number of goblet cells, the thickness of mucus layer as well as the level of expression of genes encoding for mucins are regarded as key indicators related of this barrier function $(11,12)$.

In addition, epithelial cell shedding (so called "anoikis") and the fast renewal of the intestinal epithelium (3-5 days) is another mechanism providing protection against pathogens by limiting their adherence to epithelial cells. Rapid renewal of damaged enterocytes is supported by a high protein turnover and cell proliferation, and maintenance of functional enterocytes can therefore be considered as a marker of good intestinal function $(13,14)$. Low expression of caspase- 3 in enterocytes indicates decreased apoptosis whereas increased proliferating cell nuclear antigen (protein which enhances DNA polymerase activity), mitotic index (number of cells undergoing mitosis divided by the total number of cells), and ornithine decarboxylase (protein involved in the first step of polyamine synthesis) activity are described as indicators of cellular proliferation (15).

This barrier function also relies on the sealing of epithelial cells which depends on the organization of tight junctions. Tight junctions, located at the apical side of the enterocytes, are multi 
protein complexes consisting of transmembrane proteins, such as occludin, claudins (claudin-1, claudin 2, claudin 3 ), tricellulin, and junctional adhesion molecules anchored with cytosolic molecules like zonula occludens proteins (ZO-1, ZO-2, and ZO$3)$. The abundance of these molecules is directly linked to a decrease in intestinal permeability (16). Disruption in gut barrier function increases gut permeability, occurrence of diarrhea and leaky gut syndrome.

In summary, the following parameters are considered good markers to monitor epithelial barrier and digestion: villous height, gene expression and/or protein levels of tight junctions, abundance of goblet cells or mucins, digestive enzyme activity, nutrient transporters, cell proliferation, diarrhea occurrence, intestinal permeability, cell apoptosis.

\section{Intestinal Immune Fitness}

The physical barrier function of the gut is completed by innate and acquired immunity which constitutes two additional lines of defense. The gut is an important site of immunity in the body and can be subjected to inflammatory process. Inflammation activates immunity in order to fight against an infection and/or repair tissue damage. Inflammation is related to increased demand in energy and nutrients to synthesize cytokines and acute phase protein and activate the proliferation of the immune cells (17-19). Therefore, an excessive immune response, which could be defined as an imbalance between the level of inflammation and the challenge faced by the animal, can lead to an excessive and unnecessary use of energy and nutrients.

Immune fitness could be defined as "the capacity of the host immune system to respond in an appropriate manner to a challenge and to return or stay in immune homeostatic state in the case of the absence of a challenge."

Low plasma circulating and/or low intestinal gut mucosa gene expression of proinflammatory cytokines (TNF-a, IFN-g, IL-1, IL-4, IL-6, IL-8) in the absence of a challenge and high secretion of immunoglobulins are indicators related to immune fitness. In addition, the intestinal concentration of secretory $\operatorname{IgA}$ which are a key component of mucosal defenses is an indicator of the adaptive immune response (20). Another key marker of immune fitness and inflammation is related to lymphocytes proliferation in the mucosa and their phenotype. For instance, high proportion of regulatory $\mathrm{T}$ cells in the gut mucosa (Tregs) expressing Foxp3 indicates an immunoregulatory phenotype (21).

In summary, the following parameters are considered good markers to monitor immune fitness: immunoglobulin concentrations, cytokines concentration, lymphocytes proliferation.

\section{Oxidative Stress Homeostasis}

Oxidative stress occurs when the production of reactive oxygen species (ROS) such as superoxide is not balanced by the antioxidant defense (22). In that case, ROS may cause alteration of macromolecules including lipids (marked by increased malondialdehyde), proteins and DNA leading to cellular and tissue damages. The production of ROS is a physiological mechanism, these molecules being generated in the mitochondria during aerobic cellular metabolism (22). Besides, these molecules are synthesized by the cells of the innate immune system, like granulocytes and macrophages, and the epithelial cells to defend against pathogens (23). In the intestine, the main ROS generating enzymes are NOX1 and DUOX2 produced respectively by the epithelial cells and the neutrophils (24).

A tight control of ROS concentration is of primary importance and requires a delicate balance of systems involved in their generation and degradation. Oxidative stress homeostasis is defined as a "situation where the concentration of reactive oxygen is sufficient to transduce signal and counteract pathogens but insufficient to trigger cell damages to the host."

Antioxidant system relies on the action of antioxidant molecules including vitamins such as vitamins $\mathrm{E}$ and $\mathrm{C}$ and metabolites like glutathione (GSH) in the oxidized form, and enzymes including superoxide dismutase (SOD), catalase (CAT), glutathione peroxidase (GSH-Px) and heme oxygenase (HO-1) which expression is under the control of the transcription factor Nuclear factor erythroid 2-related factor 2 (Nrf2) (25). Chaperone proteins such as HSP70 play also a role in the response to oxidative stress being involved in the removing of non-functional and potentially harmful proteins (26). Both the measurements of antioxidant molecules concentrations and antioxidant enzyme activities in the gut mucosa can be used as markers to assess oxidative status.

In summary, the following parameters are considered good markers to monitor oxidative stress at the gut level: total glutathione concentration, antioxidative enzyme expression or activity, antioxidative capacity, concentration of malondialdehyde, oxidized glutathione concentration.

\section{Microbiota Balance}

In pigs and broilers, the intestine of healthy individuals is colonized by over than 500 species of bacteria, but also by fungi and protozoans $(27,28)$. Focusing on bacteria, for which the literature is more exhaustive, is a first approach to encompass microbiota complexity. In caecum and colon, microbial species belong essentially to the phyla Firmicutes (including Clostridium, Enterococcus, Lactobacillus, and Ruminococcus genera) and Bacteroidetes (including Bacteroides and Prevotella genera) (29, 30). These bacteria are in a homeostatic balance with the host and guarantee the protection of the gut. Indeed, commensal bacteria potentially prevent the overgrowth of pathogenic ones by competing for nutrients and adhesion sites and by synthesizing short chain fatty acids (SCFA) or antimicrobial peptides. The microbiota also plays a pivotal role to degrade the non-digestible compounds producing SCFA as source of energy as well as noxious compound like ammonia or polyamines when the substrates are indigestible proteins.

Microbial ecology is a new frontier for animal science and in some way mirrors what has been done in humans. Among the approaches proposed by Vangay et al. (31) to study the microbiota, the dysbiosis-centric view can fit with the livestock science. The authors defined four changes associated with dysbiosis: loss of keystone taxa, loss of biodiversity, blooms of pathogens and pathobionts and shift in functional capability. These changes can occur independently or altogether, which is most often the case (32). Microbiota balance could therefore 
be defined as the opposite of dysbiosis meaning "a bacterial population abundant and diverse with a high contribution of beneficial bacteria (Lactobacillus, Bifidobacterium, SCFA producers) at the expense of pathogenic ones" such as enterotoxigenic Escherichia coli (ETEC), Campylobacter and Salmonella enteritidis.

In summary, the following parameters are considered good markers to monitor microbiota: microbiota diversity, abundance of beneficial bacteria, abundance of parasites, abundance of harmful bacteria.

\section{EFFECT OF GUT HEALTH CHALLENGES IN PIGS AND BROILER CHICKENS ON AMINO ACID METABOLISM}

\section{Early Weaning and Diarrhea in Piglets}

In intensive pig farms, piglets are usually weaned between 2 and 5 weeks of age, when the gut and immune system are immature. Early weaning is a critical period during which they are separated from the sow and mixed with those of other litters in a new environment (33). These changes generate a stress which usually decreases water and feed intake and in turn affects negatively the gut health $(33,34)$. It was reported that piglets, in the immediate post-weaning, exhibit intestinal villous atrophy, crypt hyperplasia and lower number of goblet cells. Altered transepithelial resistance and depressed digestive enzymatic activities are also observed in association with immune cells infiltration, upregulation of pro-inflammatory cytokines and decrease in nutrient absorption (35). Intestinal oxidative stress indicators are also increased due to a reduction of the activity or gene expression of antioxidative enzymes (36). All these changes can decrease the ability of the host to digest and absorb nutrients (37) contribute to dysbiosis and translate into the occurrence of post-weaning diarrhea (38).

In addition, both protein content and protein synthesis in the gut increase after weaning indicating a high need to support the tissue development and adaptation to this period (39). Weaning is also believed to reshape AA metabolism especially at the gut level. Indeed, at weaning, the endogenous production of arginine is blunted in enterocytes which could lead to a shortage of arginine (40). Bacterial infection involving $E$ coli, the major pathogenic bacterium involved in post-weaning diarrhea, is known to impair feed intake, modulate AA, gut and body metabolism because of the systemic inflammation induced by this infection. Two studies reported higher tryptophan requirement in piglets challenged with enterotoxigenic E. coli $(41,42)$. Accordingly, weaning under poor sanitary conditions induced a systemic inflammation that affected whole body tryptophan metabolism (43). Similar results were reported with threonine in piglets housed under challenged conditions and fed antibioticfree diets (44-46). A recent study also revealed that immune stimulation induced by bacterial endotoxin (LPS) injection also led to an increase in the fluxes of GSH synthesis together with a decrease in plasma concentration of sulfur AA cysteine, one of the three AA constituting GSH, and methionine (47). Taking together, these results suggest that weaning may increase the need for AA and that weaned piglets could particularly benefit from increased supply of arginine, sulfur AA (SAA), tryptophan and threonine.

\section{Coccidiosis Challenge in Broiler Chickens}

In broiler chickens, coccidiosis is the main challenge at the gut level, generating more than 3 billion dollars of loss every year in poultry industry (48). This challenge is caused by the infection of Eimeria species which colonize different parts of the intestinal tract. This coccidiosis decreases feed intake and growth and increases the susceptibility of necrotic enteritis leading to a further decrease in performance and increase in mortality (49).

The response of the host to the infection could be described in two phases: a damaging phase and a repairing and defense phase. As part of the damaging phase, coccidiosis is associated with decreased villus height, number of goblet cells, AA transporters and digestive enzymes leading to a lower AA availability as well as a decrease in transepithelial resistance and mucin expression (50). In addition, infection with any of the major Eimeria species leads to reduced plasma carotenoid thereby impairing protection against oxidative stress (51).

As part of the repairing and defense phase, it can be observed during coccidiosis an increase in inflammation as indicated by the increase of cytokines, nitric oxide and IgA production used to fight the parasites $(50,52)$. In addition, crypt cell proliferation occurs to replace damaged enterocytes and mucus production is enhanced to form a physical barrier against the pathogens (53). This latter effect could potentiate Clostridium perfringens colonization and necrotic enteritis as this bacteria can use intestinal mucus as a source of nutrients (49).

It has been reported that coccidiosis condition modulates AA metabolism. Indeed, it was shown that coccidiosis decreases the digestibility of nearly all AA (54). In the same study, Rochel et al. reported that coccidiosis-challenged birds had decreased plasma concentration of arginine, asparagine, glutamine, aspartate and increased concentration of ornithine, branched-chain AA (BCAA) and lysine. Interestingly, re-analysis of existing transcriptomic data from chicken cecal epithelia upon infection by Eimeria tenella (55) revealed that the expression of genes encoding for enzymes involved in threonine and arginine catabolism were increased during coccidiosis infection in the cecum (data not published) suggesting decreased availability of these amino acids for protein synthesis. To summarize, when broilers are facing coccidial or bacterial challenge, feed intake and digestibility of AA are reduced while they are showing a higher need for some of those functional AA, leading to an imbalance between supply and demand of AA in fast-growing broiler diets.

\section{ROLES OF AMINO ACIDS IN INTESTINAL HOMEOSTASIS}

As suggested in the previous part, AA seem to have an important role in the maintenance of gut health as their demand can be increased during periods of challenge in both piglets and chickens. Based on the published literature on functional AA supplementation in piglets and broilers, we summarize below 
how AA could support and restore the four pillars of gut health previously described. By "support," we refer to the way that AA can reinforce a pillar of gut health in the absence of challenge or prepare the function before a challenge. By "restore," we refer to the way that AA can help the functions to recover and go back to homeostasis after a challenge like weaning in piglets and coccidiosis in broiler chickens. By "support and restore," we refer to the way that AA prepare to a challenge and help the animal to recover. For each of the four pillars, a list of key indicators mentioned in the previous part was listed as shown in Tables 1, 2. The AA that influence these indicators related to the four pillars of gut health are listed in Table $\mathbf{1}$ by summarizing the evidence in piglets and in Table 2 by summarizing the evidence in broilers.

These two tables suggest that investigations about AA effects on gut health are scarcer in broilers than piglets. Most broiler studies are focusing on arginine, glutamine and threonine, while piglet studies are investigating a broader scope of AA. It is difficult to clearly identify different effects of AA supplementation across the two species while it is known that AA requirements and metabolism might differ in pigs and chickens. Furthermore, it is interesting to note that in both the species most studies tested very high doses of supplementation of AA (between 0.5 and $1.0 \%$ as-fed basis) which lead to level of AA far above the recommendation for growth in pigs and chickens. This could be due to the fact that studies aimed to reveal the functional properties of amino acids.

It is interesting to note that some AA, especially aspartate, arginine, cysteine, glutamate or mono sodium glutamate (MSG), and glutamine for piglets and arginine, glutamine, threonine and tryptophan for broilers are involved in three out of the four pillars of gut health confirming two main aspects: (1) these pillars are strongly interconnected and interdependent; (2) AA have different functions and can modulate several metabolic pathways and functions depending to the specific conditions.

These functional properties have been well-described in the literature and rely on the following functional properties of AA: (1) AA are energy sources and precursors of functional molecules and proteins, (2) AA modulate gene expression

TABLE 1 | Amino acids influencing the indicators related to the 4 pillars of gut health in piglets.

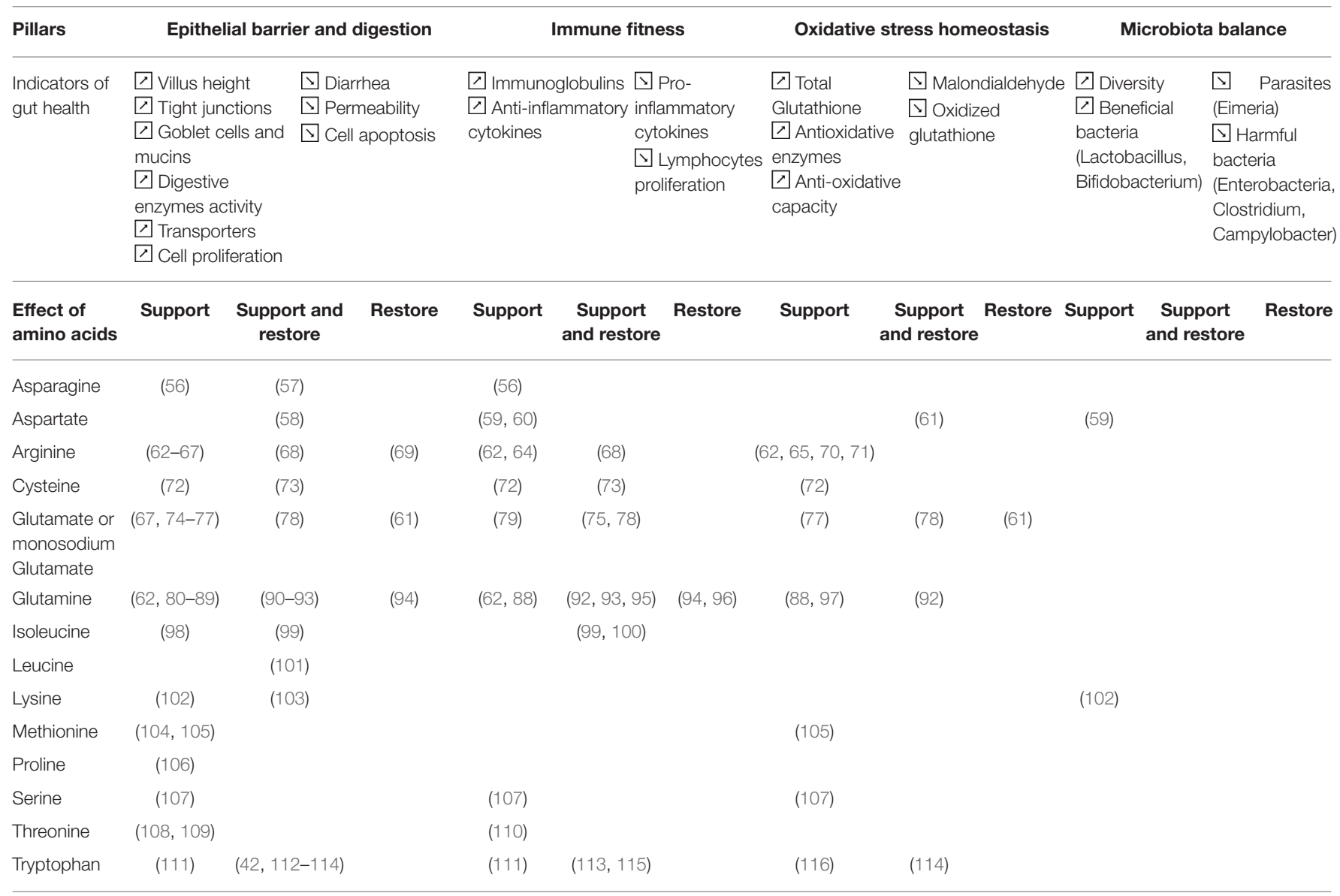

$\nabla$, increased in response to $A A$ supplementation; $\square$, decreased in response to AA supplementation. 
and protein phosphorylation and finally, (3) AA can serve as microbiota modulators.

\section{Amino Acids Are Energy Sources and Precursors of Functional Molecules and Proteins}

Several AA can serve as a source of energy for the gut epithelium and are therefore considered to favor gut development and epithelial barrier. Indeed, it has been reported that most of dietary glutamine and glutamate ( $>90 \%$ ) after conversion into $\alpha$-ketoglutarate fuel the Krebs cycle and are used as a source of energy by enterocytes (137). Accordingly, in piglets, the supplementation of feed with asparagine, aspartate, glutamine, alanyl-glutamine and MSG are associated with an increase of energy availability in the intestine as shown by higher intestinal levels of ATP, adenylate energy charge (AEC) and lower AMP:ATP ratio $(57,58,77,92)$. Similarly, the roles of glutamate and glutamine as substrate for ATP production has been reported in vitro using chicken enterocytes, glutamate being the most potent source of energy (138).

The importance of AA for gut health also relies on the abundance of particular AAs in functional proteins. For example, threonine is critical for epithelial barrier function being the most abundant indispensable AA in mucins (53). Finally, AAs are also pivotal for gut health as precursors of functional molecules. For example, glycine, glutamate and cysteine are the three AAs composing glutathione (GSH), a tripeptide synthesized in the cytosol that play a key role in the regulation of the oxidative stress through its scavenging effect on free radicals (72). The concentrations in glutathione in the small intestine (jejunum and ileum) was decreased by $50 \%$ in piglets fed a SAA-free diet compared to those fed a well-balanced diet (139).

\section{Amino Acids Can Modulate Gene Expression and Protein Phosphorylation}

In addition to being precursors of energy and functional molecules and proteins, AAs are signaling molecules; their abundance in cells directly modulates some metabolic pathways by modifying gene expression and protein phosphorylation. In piglets, leucine and glutamate supplementations in feed in vivo were able to increase the level of phosphorylation of mTOR, a major regulator of protein synthesis, and some of its downstream targets (4-EBP1, S6K) in the different parts of the gut $(75,78$, $101,140)$. In line with these results, Corl et al. (141) reported that arginine and BCAA increased the phosphorylation level of p70S6k, a downstream target of mTOR, in rotavirus-infected piglets' jejunal segments. Similarly, increasing the glycine level triggers cell proliferation, protein synthesis, phosphorylation of mTOR, 4EBP-1 and p70S6K in intestinal porcine IPEC-1 cells (142). In broiler chickens, evidence is scarce but a key role of arginine as a regulator of protein synthesis in the gut is suggested. Indeed, Tan et al. reported that supplemental dietary arginine attenuates intestinal mucosal disruption in broiler chickens during a coccidial vaccine challenge through an increase of mRNA expression of jejunal genes related to kinase activity, such as mTOR, Raptor and RP6KB1 (50). The

TABLE 2 | Amino acids influencing the indicators related to the 4 pillars of gut health in broiler chickens.

\begin{tabular}{|c|c|c|c|c|c|c|}
\hline \multirow{2}{*}{$\begin{array}{l}\text { Pillars } \\
\text { Indicators of } \\
\text { gut health }\end{array}$} & \multirow[b]{2}{*}{ 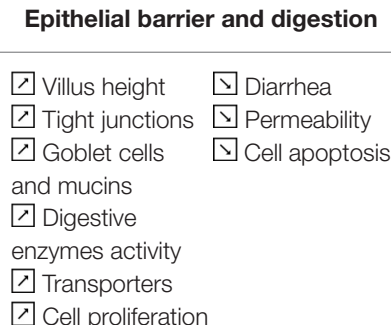 } & \multirow{2}{*}{$\begin{array}{l}\text { Immune fitness } \\
\square \text { Immunoglobulins } \square \text { Pro-inflammatory } \\
\square \text { Anti-inflammatory Cytokines } \\
\text { s cytokines } \\
\begin{array}{ll}\square \text { Lymphocytes } \\
\text { proliferation }\end{array} \\
\end{array}$} & \multicolumn{2}{|c|}{ Oxidative stress homeostasis } & \multicolumn{2}{|c|}{ Microbiota balance } \\
\hline & & & $\begin{array}{l}\square \text { Total } \\
\text { Glutathione } \\
\triangle \text { Antioxidative } \\
\text { enzymes } \\
\triangle \text { Anti-oxidative } \\
\text { capacity }\end{array}$ & $\begin{array}{l}\square \text { Malondialdehyde } \\
\square \text { Oxidized } \\
\text { glutathione }\end{array}$ & $\begin{array}{l}\nearrow \text { Diversity } \\
\nearrow \text { Beneficial } \\
\text { bacteria (eg. } \\
\text { Lactobacillus, } \\
\text { Bifidobacterium) }\end{array}$ & $\begin{array}{l}\triangle \text { Parasites } \\
\text { (Eimeria) } \\
\searrow \text { Harmful } \\
\text { bacteria (E. coli, } \\
\text { Enterobacteria, } \\
\text { Clostridium, } \\
\text { Campylobacter) }\end{array}$ \\
\hline
\end{tabular}

\begin{tabular}{|c|c|c|c|c|c|c|c|c|c|c|}
\hline $\begin{array}{l}\text { Effect of } \\
\text { amino acids }\end{array}$ & Support & $\begin{array}{l}\text { Support and Restore } \\
\text { restore }\end{array}$ & Support & $\begin{array}{l}\text { Support and } \\
\text { restore }\end{array}$ & Restore & Support & $\begin{array}{c}\text { Support } \\
\text { and restore }\end{array}$ & Restore & Support & $\begin{array}{c}\text { Support and } \\
\text { restore }\end{array}$ \\
\hline
\end{tabular}

\begin{tabular}{|c|c|c|c|c|c|c|c|c|}
\hline amino acids & & restore & & restore & & & d restore & restore \\
\hline Arginine & $(50,117,118)$ & & $(119-121$ & $, 122,1$ & & & & $(52,117,118)$ \\
\hline Glutamate & & $(124,125)$ & & & & & & \\
\hline Glutamine & $(125,126)$ & $(125,127-129)$ & (125) & (125) & & & $(127)$ & \\
\hline Glycine & $(130)$ & & & & & & & \\
\hline Lysine & & & & & & & $(131)$ & \\
\hline Methionine & & & & $(132)$ & & & $(131)$ & \\
\hline Threonine & $(130,133)$ & $(134,135)$ & (133) & (134) & (133) & (131) & & (133) \\
\hline Tryptophan & & & & (122) & & (136) & & $(136)$ \\
\hline
\end{tabular}

$\square$, increased in response to $A A$ supplementation; $\square$, decreased in response to AA supplementation. 
TABLE 3 | Main metabolites produced by amino acid metabolism by the in the gut microbiota and associated effect on gut health.



effect of AA supplementation in feed on gene expression is well-described. For example, the expression of AA and glucose transporters responds to AA supplementation, particularly to branched-chain amino acids and lysine in piglets (103) and to lysine, methionine and threonine in broiler (143) suggesting that AA supplementation could mitigate the effects of challenge and support gut health by improving nutrient absorption (144). Supplementation of glutamine to weanling diet can promote the expression of genes related with the reduction of oxidative stress (88). Similarly, SAAs can control Nrf2 expression in the liver, a transcription factor controlling the expression of antioxidant redox buffering enzymes and the production of other scavenging systems for reactive oxygen species like methionine sulphoxide reductases (145).

\section{Amino Acids Are Microbiota Modulators}

In vitro studies, based on single strains and mixed community derived by intestinal content of piglets have shown that AAs can contribute in influencing the metabolism and the development of bacteria (146-148). This suggests that AAs can regulate the gut microbiota composition and activity. This microbiotamodulating effect of AAs has already been investigated with a main focus on tryptophan and arginine.

Indeed, in weaned pigs, $0.4 \%$ tryptophan supplementation for 4 weeks increased Lactobacillus and Clostridium XI in the jejunum (111). Alpha diversity indices were enhanced in response to tryptophan supplementation in both weaned piglets (111) and fattening pigs susceptible to intestinal adhesion of ETEC F4 (149). 1.0\% arginine supplementation for 60 days in fattening pigs increased Canobacteria and in combination with $1.0 \%$ Leucine (Leu) it increased Bacteriodes and reduced Clostridium sensu stricto, Terrisporobacter and EscherichiaShigella in the colon (150). In sows, arginine supplementation increased both the Bacteroidaceae family and the Bacteroides genus in feces (151).

In broilers, it has been reported that arginine supplementation can alleviate gut injury and normalize the ileal microbiota of C. perfringens-challenged chickens (117). Furthermore, in 
broiler chickens facing a $2 \mathrm{~h}$-transportation stress, tryptophan supplementation increased the population of beneficial bacteria (Enterococci, Bifidobacteria and Lactobacilli) and reduced the population of pathogenic ones (Clostridia, Enterobacteria and Campylobacter) in the cecum digesta suggesting a positive effect of this AA on microbial balance (136). Similarly, a total SAAs supply exerted a beneficial effect in broiler cecal microbial community by increasing the alpha diversity of the microbiota and by promoting the microbial metabolisms related to carbohydrate, AA, nucleotide, and lipid (152).

The metabolism of AA by the gut microbiota releases numerous metabolites in the intestinal lumen (153). These bioactive compounds are key molecular intermediates between the microbiota and its host. Similarly to carbohydrates, AA can serve as precursors for the production of the main SCFA including acetate and butyrate that are well-known regulators of gut health (154). Moreover, some SCFA are produced exclusively from AA (isobutyrate, isovalerate, 2-methylbutyrate) but their effect on gut health has not been extensively studied (153). Recent research has highlighted the beneficial role on gut health of bacterial metabolites derived from tryptophan (indolic compounds) (155). Catabolism of AA by the gut microbiota also produces amines and polyamines such as putrescine, cadaverine and 5-aminovalerate. The effects on gut health of these metabolites are not clear yet since both beneficial and detrimental effects were described according to the studies and concentration tested (153). It is also worth noting that AA degradation by the microbiota can release toxic compounds such as deamination-derived ammonia, cysteinederived hydrogen sulfide and tyrosine derived p-cresol (153). In Table 3, we summarized the main metabolites yielded by bacterial metabolism of the AA that were tested in the in

\section{REFERENCES}

1. Pluske JR, Turpin DL, Kim J-C. Gastrointestinal tract (gut) health in the young pig. Anim Nutr. (2018) 4:187-96. doi: 10.1016/j.aninu.2017.12.004

2. Valdes AM, Walter J, Segal E, Spector TD. Role of the gut microbiota in nutrition and health. BMJ. (2018) 361:k2179. doi: 10.1136/bmj.k2179

3. Stokes CR. The development and role of microbial-host interactions in gut mucosal immune development. J Anim Sci Biotechnol. (2017) 8:12. doi: 10.1186/s40104-016-0138-0

4. Tremaroli V, Bäckhed F. Functional interactions between the gut microbiota and host metabolism. Nature. (2012) 489:242-9. doi: 10.1038/nature11552

5. Wu G. Functional amino acids in nutrition and health. Amino Acids. (2013) 45:407-11. doi: 10.1007/s00726-013-1500-6

6. Kogut MH, Arsenault RJ. Editorial: gut health: the new paradigm in food animal production. Front Vet Sci. (2016) 3:71. doi: 10.3389/fvets.2016.00071

7. Bischoff SC. "Gut health": a new objective in medicine? BMC Med. (2011) 9:24. doi: 10.1186/1741-7015-9-24

8. Zhao X, Xian Y, Li C, Wang C, Yu D, Zhu W, et al. Feeding Lactobacillus plantarum and Lactobacillus casei increased microbial diversity and short chain fatty acids production in the gut-intestinal tract of weaning piglets. Wei Sheng Wu Xue Bao. (2016) 56:1291-300. doi: 10.13343/j.cnki.wsxb.20150529-en

9. Curry SM, Schwartz KJ, Yoon KJ, Gabler NK, Burrough ER. Effects of porcine epidemic diarrhea virus infection on nursery pig intestinal function and barrier integrity. Vet Microbiol. (2017). 211:58-66. doi: 10.1016/j.vetmic.2017.09.021 vivo trial that included in the present review. We also listed the direct effects of these AA-derived metabolites on gut health. Overall, it is clear that metabolites derived from the $s$ yielded by bacterial catabolism of the AA can mediate part of the action of AA on the four pillar of gut health and more work is needed to validate this hypothesis in pigs and poultry.

\section{CONCLUDING REMARKS}

This work confirms that supplementation of free AA, based on their roles as precursors of energy and functional molecules, as signaling molecules and as microbiota modulators, can contribute to gut health of monogastric animals by supporting or restoring its four intertwined pillars. The fact that piglet and broiler gut health positively benefit from AA supplementation indicates that under challenging conditions, those AA may become indispensable for optimal performance and health. Additional work is still needed in order to take the full benefits of AA functions while decreasing the effective dose of supplementation. For this purpose, synergy between AA, effects of AA derived metabolites, difference in the metabolic fate between free and protein-bound AA are research topics that need to be furtherly investigated.

\section{AUTHOR CONTRIBUTIONS}

TC-D, WL, and EC contributed to the conception and structure of the paper. TC-D organized the literature review and wrote the first draft of the paper. TC-D, DL, NL, PB, PT, MB, and ST contributed to manuscript writing and revision. All authors approved the final version for submission.

10. Allen A, Bell A, Mantle M, Pearson JP. The structure and physiology of gastrointestinal mucus. Adv Exp Med Biol. (1982) 144:115-33. doi: 10.1007/978-1-4615-9254-9_15

11. Hussein SM, Yokhana JS, Frankel TL. Supplementing the feeds of layer pullets, at different ages with two different fiber sources improves immune function. Poult Sci. (2017) 96:2718-27. doi: 10.3382/ps/ pex051

12. Johansson MEV, Hansson GC. Mucus and the goblet cell. Dig Dis Basel Switz. (2013) 31:305-9. doi: 10.1159/000354683

13. Camilleri M, Madsen K, Spiller R, Greenwood-Van Meerveld B, Van Meerveld BG, Verne GN. Intestinal barrier function in health and gastrointestinal disease. Neurogastroenterol Motil. (2012) 24:503-12. doi: 10.1111/j.1365-2982.2012.01921.x

14. Bojarski C, Bendfeldt K, Gitter AH, Mankertz J, Fromm M, Wagner S, et al. Apoptosis and intestinal barrier function. Ann N Y Acad Sci. (2000) 915:270-4. doi: 10.1111/j.1749-6632.2000.tb05252.x

15. Nicholson DW, Thornberry NA. Caspases: killer proteases. Trends Biochem Sci. (1997) 22:299-306. doi: 10.1016/S0968-0004(97)01085-2

16. Schneeberger EE, Lynch RD. The tight junction: a multifunctional complex. Am J Physiol Cell Physiol. (2004) 286:C12131228. doi: 10.1152/ajpcell.00558.2003

17. Reeds PJ, Fjeld CR, Jahoor F. Do the differences between the amino acid compositions of acute-phase and muscle proteins have a bearing on nitrogen loss in traumatic states? J Nutr. (1994) 124:906-10. doi: 10.1093/jn/124.6.906

18. Obled C. Amino acid requirements in inflammatory states. Can J Anim Sci. (2003) 83:365-73. doi: 10.4141/A03-021 
19. Wang A, Medzhitov R. Counting calories: the cost of inflammation. Cell. (2019) 177:223-4. doi: 10.1016/j.cell.2019.03.022

20. Trevisi P, Gandolfi G, Priori D, Messori S, Colombo M, Mazzoni $\mathrm{M}$, et al. Age-related expression of the polymeric immunoglobulin receptor (pIgR) in the gastric mucosa of young pigs. PLoS ONE. (2013) 8:e81473. doi: 10.1371/journal.pone.0081473

21. Li Z, Li D, Tsun A, Li B. FOXP3 + regulatory T cells and their functional regulation. Cell Mol Immunol. (2015) 12:558-65. doi: 10.1038/cmi.2015.10

22. Yoshikawa T, Naito Y. What is oxidative stress? Jpn Med Assoc J. (2002) 45:271-6.

23. Salim T, Sershen CL, May EE. Investigating the role of TNF$\alpha$ and IFN- $\gamma$ activation on the dynamics of iNOS gene expression in lps stimulated macrophages. PLoS ONE. (2016) 11:e0153289. doi: 10.1371/journal.pone.0153289

24. Campbell EL, Colgan SP. Control and dysregulation of redox signalling in the gastrointestinal tract. Nat Rev Gastroenterol Hepatol. (2019) 16:10620. doi: 10.1038/s41575-018-0079-5

25. Ma Q. Role of Nrf2 in oxidative stress and toxicity. Ann Rev Pharmacol Toxicol. (2013) 53:401-26. doi: 10.1146/annurev-pharmtox-011112-140320

26. Ikwegbue PC, Masamba P, Oyinloye BE, Kappo AP. Roles of heat shock proteins in apoptosis, oxidative stress, human inflammatory diseases, and cancer. Pharm Basel Switz. (2017) 11:2. doi: 10.3390/ph11010002

27. Summers KL, Frey JF, Ramsay TG, Arfken AM. The piglet mycobiome during the weaning transition: a pilot studyl. J Anim Sci. (2019) 97:2889900. doi: 10.1093/jas/skz182

28. Cafarchia C, Iatta R, Danesi P, Camarda A, Capelli G, Otranto D. Yeasts isolated from cloacal swabs, feces, and eggs of laying hens. Med Mycol. (2019) 57:340-5. doi: 10.1093/mmy/myy026

29. Choi KY, Lee TK, Sul WJ. Metagenomic analysis of chicken gut microbiota for improving metabolism and health of chickens-a review. Asian-Australas J Anim Sci. (2015) 28:1217-25. doi: 10.5713/ajas.15.0026

30. Leser TD, Amenuvor JZ, Jensen TK, Lindecrona RH, Boye M, Møller K. Culture-independent analysis of gut bacteria: the pig gastrointestinal tract microbiota revisited. Appl Environ Microbiol. (2002) 68:67390. doi: 10.1128/AEM.68.2.673-690.2002

31. Vangay P, Ward T, Gerber JS, Knights D. Antibiotics, pediatric dysbiosis, and disease. Cell Host Microbe. (2015) 17:55364. doi: 10.1016/j.chom.2015.04.006

32. DeGruttola AK, Low D, Mizoguchi A, Mizoguchi E. Current understanding of dysbiosis in disease in human and animal models. Inflamm Bowel Dis. (2016) 22:1137-50. doi: 10.1097/MIB.0000000000000750

33. Pluske JR, Hampson DJ, Williams IH. Factors influencing the structure and function of the small intestine in the weaned pig: a review. Livest Prod Sci. (1997) 51:215-36. doi: 10.1016/S0301-6226(97)00057-2

34. Lallès J-P, Bosi P, Smidt $H$, Stokes CR. Nutritional management of gut health in pigs around weaning. Proc Nutr Soc. (2007) 66:2608. doi: 10.1017/S0029665107005484

35. Lallès J-P, Boudry G, Favier C, Floc'h NL, Luron I, Montagne L, et al. Gut function and dysfunction in young pigs: physiology. Anim Res. (2004) 53:301-16. doi: 10.1051/animres:2004018

36. Xiong X, Tan B, Song M, Ji P, Kim K, Yin Y, et al. Nutritional intervention for the intestinal development and health of weaned pigs. Front Vet Sci. (2019) 6:46. doi: 10.3389/fvets.2019.00046

37. Nabuurs MJA, Hoogendoorn A, Van Zijderveld FG. Effects of weaning and enterotoxigenic Escherichia coli on net absorption in the small intestine of pigs. Res Vet Sci. (1994) 56:379-85. doi: 10.1016/0034-5288(94)9 0156-2

38. Gresse R, Chaucheyras-Durand F, Fleury MA, Van de Wiele T, Forano E, Blanquet-Diot S. Gut microbiota dysbiosis in postweaning piglets: understanding the keys to health. Trends Microbiol. (2017) 25:85173. doi: 10.1016/j.tim.2017.05.004

39. Tang M, Laarveld B, Van Kessel AG, Hamilton DL, Estrada A, Patience JF. Effect of segregated early weaning on postweaning small intestinal development in pigs. J Anim Sci. (1999) 77:3191-200. doi: 10.2527/1999.77123191x

40. Wu G, Knabe DA. Arginine synthesis in enterocytes of neonatal pigs. Am J Physiol. (1995) 269(3 Pt 2):R621-629. doi: 10.1152/ajpregu.1995.269.3.R621
41. Trevisi P, Corrent E, Messori S, Formica S, Priori D, Bosi P. Supplementary tryptophan downregulates the expression of genes induced by the gut microbiota in healthy weaned pigs susceptible to enterotoxigenic Escherichia coli F4. Livest Sci. (2012) 147:96-103. doi: 10.1016/j.livsci.2012.04.008

42. Trevisi P, Melchior D, Mazzoni M, Casini L, De Filippi S, Minieri L, et al. A tryptophan-enriched diet improves feed intake and growth performance of susceptible weanling pigs orally challenged with Escherichia coli K88. J Anim Sci. (2009) 87:148-56. doi: 10.2527/jas.2007-0732

43. Le Floc'h N, Lebellego L, Matte JJ, Melchior D, Sève B. The effect of sanitary status degradation and dietary tryptophan content on growth rate and tryptophan metabolism in weaning pigs. J Anim Sci. (2009) 87:168694. doi: $10.2527 /$ jas.2008-1348

44. Jayaraman B. Evaluation of standardized ileal digestible threonine to lysine ratio and tryptophan to lysine ratio in weaned pigs fed antibiotic-free diets and subjected to immune challenge. (2019). Available online at: https:// mspace.lib.umanitoba.ca/xmlui/handle/1993/34498 (accessed July 23, 2020).

45. Jayaraman B, Htoo J, Nyachoti CM. Effects of dietary threonine:lysine ratioes and sanitary conditions on performance, plasma urea nitrogen, plasma-free threonine and lysine of weaned pigs. Anim Nutr. (2015) 1:2838. doi: 10.1016/j.aninu.2015.09.003

46. Trevisi P, Corrent E, Mazzoni M, Messori S, Priori D, Gherpelli Y, et al. Effect of added dietary threonine on growth performance, health, immunity and gastrointestinal function of weaning pigs with differing genetic susceptibility to Escherichia coli infection and challenged with E. coli K88ac. J Anim Physiol Anim Nutr. (2015) 99:511-20. doi: 10.1111/jpn.12216

47. Rakhshandeh A, de Lange CFM, Htoo JK, Gheisari A, Rakhshandeh AR. Immune system stimulation increases the plasma cysteine flux and wholebody glutathione synthesis rate in starter pigs. J Anim Sci. (2019) 97:387181. doi: 10.1093/jas/skz211

48. High Cost of Coccidiosis in Broilers. Available online at: https:// thepoultrysite.com/news/2013/02/high-cost-of-coccidiosis-in-broilers (June 27, 2019).

49. Dahiya JP, Wilkie DC, Van Kessel AG, Drew MD. Potential strategies for controlling necrotic enteritis in broiler chickens in post-antibiotic era. Anim Feed Sci Technol. (2006) 129:60-88. doi: 10.1016/j.anifeedsci.2005.12.003

50. Tan J, Applegate TJ, Liu S, Guo Y, Eicher SD. Supplemental dietary L-arginine attenuates intestinal mucosal disruption during a coccidial vaccine challenge in broiler chickens. Br J Nutr. (2014) 112:1098109. doi: 10.1017/S0007114514001846

51. Rochell, SJ. Eimeria acervulina infection and amino acid nutrition in broiler chickens (Doctoral dissertation), University of Illinois at UrbanaChampaign, Champaign, IL (2015).

52. Allen PC. Effects of daily oral doses of L-arginine on coccidiosis infections in chickens. Poult Sci. (1999) 78:1506-9. doi: 10.1093/ps/78.11.1506

53. Bortoluzzi C, Rochell SJ, Applegate TJ. Threonine, arginine, and glutamine: Influences on intestinal physiology, immunology, and microbiology in broilers. Poult Sci. (2018) 97:937-45. doi: 10.3382/ps/pex394

54. Rochell SJ, Parsons CM, Dilger RN. Effects of Eimeria acervulina infection severity on growth performance, apparent ileal amino acid digestibility, and plasma concentrations of amino acids, carotenoids, and $\alpha 1$-acid glycoprotein in broilers. Poult Sci. (2016) 95:1573-81. doi: 10.3382/ps/pew035

55. Guo A, Cai J, Gong W, Yan H, Luo X, Tian G, et al. Transcriptome analysis in chicken cecal epithelia upon infection by Eimeria tenella in vivo. PLoS ONE. (2013) 8:e64236. doi: 10.1371/journal.pone.0064236

56. Chen S, Liu Y, Wang X, Wang H, Li S, Shi H, et al. Asparagine improves intestinal integrity, inhibits TLR4 and NOD signaling, and differently regulates p38 and ERK1/2 signaling in weanling piglets after LPS challenge. Innate Immun. (2016) 22:577-87. doi: 10.1177/1753425916664124

57. Wang X, Liu Y, Li S, Pi D, Zhu H, Hou Y, et al. Asparagine attenuates intestinal injury, improves energy status and inhibits AMPactivated protein kinase signalling pathways in weaned piglets challenged with Escherichia coli lipopolysaccharide. Br J Nutr. (2015) 114:55365. doi: 10.1017/S0007114515001877

58. Pi D, Liu Y, Shi H, Li S, Odle J, Lin X, et al. Dietary supplementation of aspartate enhances intestinal integrity and energy status in weanling piglets after lipopolysaccharide challenge. J Nutr Biochem. (2014) 25:45662. doi: 10.1016/j.jnutbio.2013.12.006 
59. Li Y, Han H, Yin J, He X, Tang Z, Li T, et al. D- and L-Aspartate regulates growth performance, inflammation and intestinal microbial community in young pigs. Food Funct. (2019) 10:1028-37. doi: 10.1039/C8FO01410H

60. Wang $\mathrm{H}$, Liu $\mathrm{Y}$, Shi $\mathrm{H}$, Wang $\mathrm{X}$, Zhu $\mathrm{H}$, Pi D, et al. Aspartate attenuates intestinal injury and inhibits TLR4 and NODs/NF- $\kappa$ B and p38 signaling in weaned pigs after LPS challenge. Eur J Nutr. (2017) 56:143343. doi: 10.1007/s00394-016-1189-x

61. Yin J, Liu M, Ren W, Duan J, Yang G, Zhao Y, et al. Effects of dietary supplementation with glutamate and aspartate on diquat-induced oxidative stress in piglets. PLoS ONE. (2015) 10:e0122893. doi: 10.1371/journal.pone.0122893

62. Wu L, Wang W, Yao K, Zhou T, Yin J, Li T, et al. Effects of dietary arginine and glutamine on alleviating the impairment induced by deoxynivalenol stress and immune relevant cytokines in growing pigs. PLoS ONE. (2013) 8:e69502. doi: 10.1371/journal.pone.0069502

63. Zhan Z, Ou D, Piao X, Kim SW, Liu Y, Wang J. Dietary arginine supplementation affects microvascular development in the small intestine of early-weaned pigs. J Nutr. (2008) 138:1304-9. doi: 10.1093/jn/138.7.1304

64. Liu Y, Huang J, Hou Y, Zhu H, Zhao S, Ding B, et al. Dietary arginine supplementation alleviates intestinal mucosal disruption induced by Escherichia coli lipopolysaccharide in weaned pigs. Br J Nutr. (2008) 100:552-60. doi: 10.1017/S0007114508911612

65. Yao K, Guan S, Li T, Huang R, Wu G, Ruan Z, et al. Dietary Larginine supplementation enhances intestinal development and expression of vascular endothelial growth factor in weanling piglets. Br J Nutr. (2011) 105:703-9. doi: 10.1017/S000711451000365X

66. Wu X, Ruan Z, Gao Y, Yin Y, Zhou X, Wang L, et al. Dietary supplementation with L-arginine or $\mathrm{N}$-carbamylglutamate enhances intestinal growth and heat shock protein-70 expression in weanling pigs fed a corn- and soybean meal-based diet. Amino Acids. (2010) 39:831-9. doi: 10.1007/s00726-010-0538-y

67. Ewtushik A, Bertolo R, Ball RO. Intestinal development of earlyweaned piglets receiving diets supplemented with selected amino acids or polyamines. Can J Anim Sci. (2000) 80:653-62. doi: 10.4141/A99-134

68. Zhu HL, Liu YL, Xie XL, Huang JJ, Hou YQ. Effect of L-arginine on intestinal mucosal immune barrier function in weaned pigs after Escherichia coli LPS challenge. Innate Immun. (2013) 19:242-52. doi: 10.1177/1753425912456223

69. Dietary L-arginine Supplementation Improves Intestinal Function in Weaned Pigs after an Escherichia coli Lipopolysaccharide Challenge. Available online at: https://www.ajas.info/journal/view.php?number=22205 (accessed June 19, 2019).

70. Bergeron N, Robert C, Guay F. Feed supplementation with arginine and zinc on antioxidant status and inflammatory response in challenged weanling piglets. Anim Nutr Zhongguo Xu Mu Shou Yi Xue Hui. (2017) 3:23646. doi: 10.1016/j.aninu.2017.06.009

71. Bergeron N, Robert C, Guay Fric. Antioxidant status and inflammatory response in weanling piglets fed diets supplemented with arginine and zinc. Can J Anim Sci. (2013) 94:87-97. doi: 10.4141/cjas2013-023

72. Song Z he, Tong G, Xiao K, Jiao L fei, Ke Y lu, Hu C hong. L-cysteine protects intestinal integrity, attenuates intestinalinflammation and oxidant stress, and modulates NF- $\mathrm{BB}$ and Nrf2 pathways in weaned piglets after LPS challenge. Innate Immun. (2016) 22:152-61. doi: 10.1177/1753425916632303

73. Kim C, Kovacs-Nolan J, Yang C, Archbold T, Fan M, Mine Y. L-cysteine supplementation attenuates local inflammation and restores gut homeostasis in a porcine model of colitis. Biochim Biophys Acta BBA-Gen Subj. (2009) 1790:1161-9. doi: 10.1016/j.bbagen.2009.05.018

74. Wu X, Zhang Y, Liu Z, Li TJ, Yin YL. Effects of oral supplementation with glutamate or combination of glutamate and $\mathrm{N}$-carbamylglutamate on intestinal mucosa morphology and epithelium cell proliferation in weanling piglets. J Anim Sci. (2012) 90(Suppl 4):337-9. doi: 10.2527/jas.53752

75. Qin Q, Xu X, Wang X, Wu H, Zhu H, Hou Y, et al. Glutamate alleviates intestinal injury, maintains mTOR and suppresses TLR4 and NOD signaling pathways in weanling pigs challenged with lipopolysaccharide. Sci Rep. (2018) 8:15124. doi: 10.1038/s41598-018-33345-7

76. Lin $\mathrm{M}$, Zhang $\mathrm{B}$, Yu C, Li J, Zhang L, Sun H, et al. LGlutamate supplementation improves small intestinal architecture and enhances the expressions of jejunal mucosa amino acid receptors and transporters in weaning piglets. PLOS ONE. (2014) 9:e111950. doi: 10.1371/journal.pone.0111950

77. Rezaei R, Knabe DA, Tekwe CD, Dahanayaka S, Ficken MD, Fielder SE, et al. Dietary supplementation with monosodium glutamate is safe and improves growth performance in postweaning pigs. Amino Acids. (2013) 44:911-23. doi: 10.1007/s00726-012-1420-x

78. Wu M, Xiao H, Ren W, Yin J, Tan B, Liu G, et al. Therapeutic effects of glutamic acid in piglets challenged with deoxynivalenol. PLoS ONE. (2014) 9:e100591. doi: 10.1371/journal.pone.0100591

79. Moore KL, Mullan BP, Pluske JR, Kim JC, D'Souza DN. The use of nucleotides, vitamins and functional amino acids to enhance the structure of the small intestine and circulating measures of immune function in the post-weaned piglet. Anim Feed Sci Technol. (2011) 165:18490. doi: 10.1016/j.anifeedsci.2010.09.013

80. Domeneghini C, Di Giancamillo A, Bosi G, Arrighi S. Can nutraceuticals affect the structure of intestinal mucosa? Qualitative and quantitative microanatomy in L-glutamine diet-supplemented weaning piglets. Vet Res Commun. (2006) 30:331-42. doi: 10.1007/s11259-006-3236-1

81. He L, Li H, Huang N, Tian J, Liu Z, Zhou X, et al. Effects of alphaketoglutarate on glutamine metabolism in piglet enterocytes in vivo and in vitro. J Agric Food Chem. (2016) 64:2668-73. doi: 10.1021/acs.jafc.6b00433

82. Wu G, Meier SA, Knabe DA. Dietary glutamine supplementation prevents jejunal atrophy in weaned pigs. J Nutr. (1996) 126:257884. doi: $10.1093 / \mathrm{jn} / 126.10 .2578$

83. Lee D-N, Cheng Y-H, Wu F-Y, Sato H, Shinzato I, Chen S-P, et al. Effect of Dietary Glutamine Supplement on Performance and Intestinal Morphology of Weaned Pigs. Asian-Australas J Anim Sci. (2003) 16:17706. doi: 10.5713/ajas.2003.1770

84. Xing S, Zhang B, Lin M, Zhou P, Li J, Zhang L, et al. Effects of alanyl-glutamine supplementation on the small intestinal mucosa barrier in weaned piglets. Asian-Australas J Anim Sci. (2017) 30:23645. doi: 10.5713/ajas.16.0077

85. Cabrera RA, Usry JL, Arrellano C, Nogueira ET, Kutschenko M, Moeser $\mathrm{AJ}$, et al. Effects of creep feeding and supplemental glutamine or glutamine plus glutamate (Aminogut) on pre- and post-weaning growth performance and intestinal health of piglets. J Anim Sci Biotechnol. (2013) 4:29. doi: 10.1186/2049-1891-4-29

86. Liu T, Peng J, Xiong Y, Zhou S, Cheng X. Effects of dietary glutamine and glutamate supplementation on small intestinal structure, active absorption and DNA, RNA concentrations in skeletal muscle tissue of weaned piglets during d 28 to 42 of age. Asian-Australas J Anim Sci. (2002) 15:23842. doi: 10.5713/ajas.2002.238

87. Zou XT, Zheng GH, Fang XJ, Jiang JF. Effects of glutamine on growth performance of weanling piglets. Czech J Anim Sci - UZPI Czech Repub. (2006). Available online at: http://agris.fao.org/agris-search/search. do? recordID=CZ2007000169 (accessed June 20, 2019).

88. Wang J, Chen L, Li P, Li X, Zhou H, Wang F, et al. Gene expression is altered in piglet small intestine by weaning and dietary glutamine supplementation. J Nutr. (2008) 138:1025-32. doi: 10.1093/jn/138.6.1025

89. Ewaschuk JB, Murdoch GK, Johnson IR, Madsen KL, Field CJ. Glutamine supplementation improves intestinal barrier function in a weaned piglet model of Escherichia coli infection. $\mathrm{Br} J$ Nutr. (2011) 106:870-7. doi: 10.1017/S0007114511001152

90. Yi G, Carroll J, Allee G, Gaines A, Kendall D, Usry J, et al. Effect of glutamine and spray-dried plasma on growth performance, small intestinal morphology, and immune responses of Escherichia coli K88+challenged weaned pigs. J Anim Sci. (2005) 83:634-43. doi: 10.2527/2005.83 $3634 \mathrm{x}$

91. Zhong X, Zhang XH, Li XM, Zhou YM, Li W, Huang XX, et al. Intestinal growth and morphology is associated with the increase in heat shock protein 70 expression in weaning piglets through supplementation with glutamine. J Anim Sci. (2011) 89:3634-42. doi: 10.2527/jas.20 10-3751

92. Haynes TE, Li P, Li X, Shimotori K, Sato H, Flynn NE, et al. L-Glutamine or L-alanyl-L-glutamine prevents oxidant- or endotoxininduced death of neonatal enterocytes. Amino Acids. (2009) 37:13142. doi: $10.1007 / \mathrm{s} 00726-009-0243-\mathrm{x}$ 
93. Domeneghini C, Di Giancamillo A, Savoini G, Paratte R, Bontempo V, Dell'Orto V. Structural patterns of swine ileal mucosa following Lglutamine and nucleotide administration during the weaning period. An histochemical and histometrical study. Histol Histopathol. (2004) 19:4958. doi: 10.14670/HH-19.49

94. Johnson JS, Lay DC. Evaluating the behavior, growth performance, immune parameters, and intestinal morphology of weaned piglets after simulated transport and heat stress when antibiotics are eliminated from the diet or replaced with L-glutamine. J Anim Sci. (2017) 95:91102. doi: $10.2527 /$ jas. 2016.1070

95. Hsu CB, Lee JW, Huang HJ, Wang CH, Lee TT, Yen HT, et al. Effects of supplemental glutamine on growth performance, plasma parameters and LPS-induced immune response of weaned barrows after castration. AsianAustralas J Anim Sci. (2012) 25:674-81. doi: 10.5713/ajas.2011.11359

96. Duttlinger AW, Kpodo KR, Lay Jr DC, Richert BT, Johnson JS. Replacing dietary antibiotics with $0.20 \% \mathrm{~L}$-glutamine in swine nursery diets: Impact on health and productivity of pigs following weaning and transport. J Anim Sci. (2019) 97:2035-52. doi: 10.1093/jas/skz098

97. Effects of Dietary Arginine and Glutamine on Alleviating the Impairment Induced by Deoxynivalenol Stress and Immune Relevant Cytokines in Growing Pigs. Available online at: https://journals.plos.org/plosone/article? id=10.1371/journal.pone.0069502 (accessed June 19, 2019).

98. Zhang S, Yang Q, Ren M, Qiao S, He P, Li D, et al. Effects of isoleucine on glucose uptake through the enhancement of muscular membrane concentrations of GLUT1 and GLUT4 and intestinal membrane concentrations of $\mathrm{Na}+$ /glucose co-transporter 1 (SGLT-1) and GLUT2. $\mathrm{Br} J$ Nutr. (2016) 116:593-602. doi: 10.1017/S0007114516002439

99. Mao X, Gu C, Ren M, Chen D, Yu B, He J, et al. l-Isoleucine administration alleviates rotavirus infection and immune response in the weaned piglet model. Front Immunol. (2018) 9:1654. doi: 10.3389/fimmu.2018.01654

100. Ren M, Cai S, Zhou T, Zhang S, Li S, Jin E, et al. Isoleucine attenuates infection induced by $\mathrm{E}$. coli challenge through the modulation of intestinal endogenous antimicrobial peptide expression and the inhibition of the increase in plasma endotoxin and IL-6 in weaned pigs. Food Funct. (2019) 10:3535-42. doi: 10.1039/C9FO00218A

101. Mao X, Liu M, Tang J, Chen H, Chen D, Yu B, et al. Dietary leucine supplementation improves the mucin production in the jejunal mucosa of the weaned pigs challenged by porcine rotavirus. PLOS ONE. (2015) 10:e0137380. doi: 10.1371/journal.pone.0137380

102. Zhou H, Chen D, Mao X, He J, Yu J, Zheng P, et al. Effects of dietary lysine levels on jejunal expression of aminoacids transporters and hindgut microflora in weaned pigs. J. Anim. Feed Sci. (2018) 27:23847. doi: $10.22358 / \mathrm{jafs} / 93736 / 2018$

103. He L, Yang H, Hou Y, Li T, Fang J, Zhou X, et al. Effects of dietary L-lysine intake on the intestinal mucosa and expression of CAT genes in weaned piglets. Amino Acids. (2013) 45:383-91. doi: 10.1007/s00726-013-1514-0

104. Zeitz JO, Kaltenböck S, Most E, Eder K. Antioxidant status and expression of inflammatory genes in gut and liver of piglets fed different dietary methionine concentrations. J Anim Physiol Anim Nutr. (2017) 101:116674. doi: $10.1111 /$ jpn.12633

105. Chen Y, Li D, Dai Z, Piao X, Wu Z, Wang B, et al. L-methionine supplementation maintains the integrity and barrier function of the smallintestinal mucosa in post-weaning piglets. Amino Acids. (2014) 46:113142. doi: 10.1007/s00726-014-1675-5

106. Wang J, Li GR, Tan BE, Xiong X, Kong XF, Xiao DF, et al. Oral administration of putrescine and proline during the suckling period improves epithelial restitution after early weaning in piglets. J Anim Sci. (2015) 93:167988. doi: $10.2527 /$ jas.2014-8230

107. Zhou X, Zhang Y, Wu X, Wan D, Yin Y. Effects of dietary serine supplementation on intestinal integrity, inflammation and oxidative status in early-weaned piglets. Cell Physiol Biochem. (2018) 48:9931002. doi: $10.1159 / 000491967$

108. Wang W, Zeng X, Mao X, Wu G, Qiao S. Optimal dietary true ileal digestible threonine for supporting the mucosal barrier in small intestine of weanling pigs. J Nutr. (2010) 140:981-6. doi: 10.3945/jn.109.118497

109. Fernández JA, Strathe A. Dietary tryptophan and threonine supply to 28 days old weaned piglets. Anim Feed Sci Technol. (2009) 154:26570. doi: 10.1016/j.anifeedsci.2009.09.003
110. Wang X, Qiao SY, Liu M, Ma YX. Effects of graded levels of true ileal digestible threonine on performance, serum parameters and immune function of 10-25kg pigs. Anim Feed Sci Technol. (2006) 129:26478. doi: 10.1016/j.anifeedsci.2006.01.003

111. Liang H, Dai Z, Liu N, Ji Y, Chen J, Zhang Y, et al. Dietary Ltryptophan modulates the structural and functional composition of the intestinal microbiome in weaned piglets. Front Microbiol. (2018) 9:1736. doi: 10.3389/fmicb.2018.01736

112. Koopmans SJ, Guzik AC, van der Meulen J, Dekker R, Kogut J, Kerr BJ, et al. Effects of supplemental L-tryptophan on serotonin, cortisol, intestinal integrity, and behavior in weanling piglets. J Anim Sci. (2006) 84:96371. doi: $10.2527 / 2006.844963 x$

113. Kim CJ, Kovacs-Nolan JA, Yang C, Archbold T, Fan MZ, Mine Y. 1Tryptophan exhibits therapeutic function in a porcine model of dextran sodium sulfate (DSS)-induced colitis. J Nutr Biochem. (2010) 21:46875. doi: 10.1016/j.jnutbio.2009.01.019

114. Liu J, Zhang Y, Li Y, Yan H, Zhang H. L-tryptophan enhances intestinal integrity in diquat-challenged piglets associated with improvement of redox status and mitochondrial function. Animals. (2019) 9:266. doi: 10.3390/ani9050266

115. Capozzalo MM, Kim JC, Htoo JK, de Lange CFM, Mullan BP, Hansen CF, et al. Effect of increasing the dietary tryptophan to lysine ratio on plasma levels of tryptophan, kynurenine and urea and on production traits in weaner pigs experimentally infected with an enterotoxigenic strain of Escherichia coli. Arch Anim Nutr. (2015) 69:17-29. doi: 10.1080/1745039X.2014.99 5972

116. Shen YB, Voilqué G, Kim JD, Odle J, Kim SW. Effects of increasing tryptophan intake on growth and physiological changes in nursery pigs. $J$ Anim Sci. (2012) 90:2264-75. doi: 10.2527/jas.2011-4203

117. Zhang B, Lv Z, Li Z, Wang W, Li G, Guo Y. Dietary l-arginine supplementation alleviates the intestinal injury and modulates the gut microbiota in broiler chickens challenged by clostridium perfringens. Front Microbiol. (2018) 9:1716. doi: 10.3389/fmicb.2018.01716

118. Laika M, Jahanian R. Increase in dietary arginine level could ameliorate detrimental impacts of coccidial infection in broiler chickens. Livest Sci. (2017) 195:38-44. doi: 10.1016/j.livsci.2016.11.002

119. Tayade C, Jaiswal T, Mishra S, Koti M. L-Arginine stimulates immune response in chickens immunized with intermediate plus strain of infectious bursal disease vaccine. Vaccine. (2006) 24:552-60. doi: 10.1016/j.vaccine.2005.08.059

120. Abdukalykova S, Ruiz-Feria CA. Arginine and vitamin E improve the cellular and humoral immune response of broiler chickens. Int J Poult Sci. (2006) 5:121-7. doi: 10.3923/ijps.2006.121.127

121. Jahanian R. Immunological responses as affected by dietary protein and arginine concentrations in starting broiler chicks. Poult Sci. (2009) 88:181824. doi: $10.3382 /$ ps.2008-00386

122. Emadi M, Jahanshiri F, Kaveh K, Hair-Bejo M, Ideris A, Alimon AR. Nutrition and immunity: the effects of the combination of arginine and tryptophan on growth performance, serum parameters and immune response in broiler chickens challenged with infectious bursal disease vaccine. Avian Pathol J WVPA. (2011) 40:63-72. doi: 10.1080/03079457.2010.539590

123. Tan J, Liu S, Guo Y, Applegate TJ, Eicher SD. Dietary Larginine supplementation attenuates lipopolysaccharide-induced inflammatory response in broiler chickens. Br J Nutr. (2014) 111:1394-404. doi: 10.1017/S0007114513003863

124. Porto ML, Givisiez PEN, Saraiva EP, Costa FGP, Filho AM, Andrade MFS, et al. Glutamic acid improves body weight gain and intestinal morphology of broiler chickens submitted to heat stress. Rev Bras Ciênc Avícola. (2015) 17:355-62. doi: 10.1590/1516-635x1703355-362

125. Bartell SM, Batal AB. The effect of supplemental glutamine on growth performance, development of the gastrointestinal tract, and humoral immune response of broilers. Poult Sci. (2007) 86:1940-7. doi: 10.1093/ps/86.9.1940

126. Wang $\mathrm{H}$, Zhang $\mathrm{C}$, Wu G, Sun $\mathrm{Y}$, Wang B, He B, et al. Glutamine enhances tight junction protein expression and modulates corticotropin-releasing factor signaling in the jejunum of weanling piglets. J Nutr. (2015) 145:2531. doi: $10.3945 /$ jn. 114.202515 
127. Moine L, Díaz de Barboza G, Pérez A, Benedetto M, Tolosa de Talamoni N. Glutamine protects intestinal calcium absorption against oxidative stress and apoptosis. Comp Biochem Physiol A Mol Integr Physiol. (2017) 212:6471. doi: 10.1016/j.cbpa.2017.07.006

128. Silva A, Maiorka A, Borges S, Santin E, Boleli I, Macari M. Surface area of the tip of the enterocytes in small intestine mucosa of broilers submitted to early feed restriction and supplemented with glutamine. Int J Poult Sci. (2007) 31-5. doi: 10.3923/ijps.2007.31.35

129. Jazideh F, Farhoomand P, Daneshyar M, Najafi G. The effects of dietary glutamine supplementation on growth performance and intestinal morphology of broiler chickens reared under hot conditions. Turk J Vet Anim Sci. (2014) 38:264-70. doi: 10.3906/vet-1210-32

130. Ospina-Rojas IC, Murakami AE, Oliveira C a. L, Guerra AFQG. Supplemental glycine and threonine effects on performance, intestinal mucosa development, and nutrient utilization of growing broiler chickens. Poult Sci. (2013) 92:2724-31. doi: 10.3382/ps.2013-03171

131. El-Katcha MI, Soltan MA, El-Shall NA, El-Desoky AM. Effect of high dietary level of some amino acids and coccidial infection on growth performance and health status of broiler chicken. Alex J Vet Sci. (2018) 58:147-65. doi: 10.5455/ajvs.281585

132. Wu B, Li L, Ruan T, Peng X. Effect of methionine deficiency on duodenal and jejunal IgA + B cell count and immunoglobulin level of broilers. Iran J Vet Res. (2018) 19:165-71. doi: 10.22099/ijvr.2018.4945

133. Chen YP, Cheng YF, Li XH, Yang WL, Wen C, Zhuang S, et al. Effects of threonine supplementation on the growth performance, immunity, oxidative status, intestinal integrity, and barrier function of broilers at the early age. Poult Sci. (2017) 96:405-13. doi: 10.3382/ps/pew240

134. Chen Y, Zhang H, Cheng Y, Li Y, Wen C, Zhou Y. Dietary l-threonine supplementation attenuates lipopolysaccharide-induced inflammatory responses and intestinal barrier damage of broiler chickens at an early age. Br J Nutr. (2018) 119:1254-62. doi: 10.1017/S0007114518000740

135. Al-Sagan AA, Khalil S, Smith MP, Al-Sagan AA, Khalil S, Smith MP. The benefit of L-threonine supplementation on growth performance, carcass characteristics, intestinal morphology and litter quality of broilers. Braz J Poult Sci. (2018) 20:753-8. doi: 10.1590/1806-9061-2018-0764

136. Bello AU, Idrus Z, Meng GY, Awad EA, Farjam AS. Gut microbiota and transportation stress response affected by tryptophan supplementation in broiler chickens. Ital J Anim Sci. (2018) 17:107-13. doi: 10.1080/1828051X.2017.1340814

137. Watford M. Glutamine and glutamate: Nonessential or essential amino acids? Anim Nutr. (2015) 1:119-22. doi: 10.1016/j.aninu.2015.08.008

138. He W. Utilization of energy substrates by chicken and pig enterocytes (Thesis), Texas A\&M University, College Station, TX, USA (2019).

139. Bauchart-Thevret C, Stoll B, Burrin DG. Intestinal metabolism of sulfur amino acids. Nutr Res Rev. (2009) 22:17587. doi: 10.1017/S0954422409990138

140. Hou Y, Wang L, Ding B, Liu Y, Zhu H, Liu J, et al. Dietary $\alpha$-ketoglutarate supplementation ameliorates intestinal injury in lipopolysaccharide-challenged piglets. Amino Acids. (2010) 39:555-64. doi: 10.1007/s00726-010-0473-y

141. Corl BA, Odle J, Niu X, Moeser AJ, Gatlin LA, Phillips OT, et al. Arginine activates intestinal p70S6 $\mathrm{k}$ and protein synthesis in piglet rotavirus enteritis. J Nutr. (2008) 138:24-9. doi: 10.1093/jn/138.1.24

142. Wang W, Wu Z, Lin G, Hu S, Wang B, Dai Z, et al. Glycine stimulates protein synthesis and inhibits oxidative stress in pig small intestinal epithelial cells. $J$ Nutr. (2014) 144:1540-8. doi: 10.3945/jn.114.194001

143. Osmanyan AK, Ghazi Harsini S, Mahdavi R, Fisinin VI, Arkhipova AL, Glazko TT, et al. Intestinal amino acid and peptide transporters in broiler are modulated by dietary amino acids and protein. Amino Acids. (2018) 50:353-7. doi: 10.1007/s00726-017-2510-6

144. Zhang S, Qiao S, Ren M, Zeng X, Ma X, Wu Z, et al. Supplementation with branched-chain amino acids to a low-protein diet regulates intestinal expression of amino acid and peptide transporters in weanling pigs. Amino Acids. (2013) 45:1191-205. doi: 10.1007/s00726-0131577-y

145. Li H, Cai L, Liang M, Wang Z, Zhang Y, Wu Q, et al. Methionine augments endogenous antioxidant capacity of rice protein through stimulating MSR antioxidant system and activating Nrf2-ARE pathway in growing and adult rats. Eur Food Res Technol. (2020) 246:105163. doi: 10.1007/s00217-020-03464-5

146. Dai Z-L, Li X-L, Xi P-B, Zhang J, Wu G, Zhu W-Y. Metabolism of select amino acids in bacteria from the pig small intestine. Amino Acids. (2012) 42:1597-608. doi: 10.1007/s00726-011-0846-X

147. Dai Z-L, Li X-L, Xi P-B, Zhang J, Wu G, Zhu W-Y. Regulatory role for L-arginine in the utilization of amino acids by pig smallintestinal bacteria. Amino Acids. (2012) 43:233-44. doi: 10.1007/s00726-011$1067-z$

148. Dai Z-L, Zhang J, Wu G, Zhu W-Y. Utilization of amino acids by bacteria from the pig small intestine. Amino Acids. (2010) 39:120115. doi: 10.1007/s00726-010-0556-9

149. Messori S, Trevisi P, Simongiovanni A, Priori D, Bosi P. Effect of susceptibility to enterotoxigenic Escherichia coli F4 and of dietary tryptophan on gut microbiota diversity observed in healthy young pigs. Vet Microbiol. (2013) 162:173-9. doi: 10.1016/j.vetmic.2012. 09.001

150. Hu C, Li F, Duan Y, Yin Y, Kong X. Dietary supplementation with leucine or in combination with arginine decreases body fat weight and alters gut microbiota composition in finishing pigs. Front Microbiol. (2019) 10:1767. doi: 10.3389/fmicb.2019.01767

151. Luise D, Bertocchi M, Bosi P, Correa F, Spinelli E, Trevisi P. Contribution of L-Arginine supplementation during gestation on sow productive performance and on sow microbial faecal profile. Ital J Anim Sci. (2020) 19:330-40. doi: 10.1080/1828051X.2020.1743210

152. Kumar S, Adhikari P, Oakley B, Kim WK. Changes in cecum microbial community in response to total sulfur amino acid (TSAA: DL-methionine) in antibiotic-free and supplemented poultry birds. Poult Sci. (2019) 98:5809-19. doi: $10.3382 / \mathrm{ps} / \mathrm{pez} 380$

153. Beaumont M, Blachier F. Amino acids in intestinal physiology and health. In: Wu G, editor. Amino Acids in Nutrition and Health. Advances in Experimental Medicine and Biology, Vol. 1265. Cham: Springer (2020). doi: 10.1007/978-3-030-45328-2_1

154. Koh A, De Vadder F, Kovatcheva-Datchary P, Bäckhed F. From dietary fiber to host physiology: short-chain fatty acids as key bacterial metabolites. Cell. (2016) 165:1332-45. doi: 10.1016/j.cell.2016.05.041

155. Roager HM, Licht TR. Microbial tryptophan catabolites in health and disease. Nat Commun. (2018) 9:3294. doi: 10.1038/s41467-018-05 470-4

156. Portune KJ, Beaumont M, Davila A-M, Tomé D, Blachier F, Sanz Y. Gut microbiota role in dietary protein metabolism and health-related outcomes: the two sides of the coin. Trends Food Sci Technol. (2016) 57:21332. doi: 10.1016/j.tifs.2016.08.011

157. Oliphant K, Allen-Vercoe E. Macronutrient metabolism by the human gut microbiome: major fermentation by-products and their impact on host health. Microbiome. (2019) 7:91. doi: 10.1186/s40168-019-0704-8

158. Davila A-M, Blachier F, Gotteland M, Andriamihaja M, Benetti P-H, Sanz $\mathrm{Y}$, et al. Re-print of "Intestinal luminal nitrogen metabolism: Role of the gut microbiota and consequences for the host." Pharmacol Res. (2013) 69:114-26. doi: 10.1016/j.phrs.2013.01.003

159. Pieper R, Tudela CV, Taciak M, Bindelle J, Pérez JF, Zentek J. Health relevance of intestinal protein fermentation in young pigs. Anim Health Res Rev. (2016) 17:137-47. doi: 10.1017/S1466252316000141

160. Blachier F, Beaumont M, Kim E. Cysteine-derived hydrogen sulfide and gut health: a matter of endogenous or bacterial origin. Curr Opin Clin Nutr Metab Care. (2019) 22:68-75. doi: 10.1097/MCO.000000000000 0526

161. Boudry G, Jamin A, Chatelais L, Gras-Le Guen C, Michel C, Le HuërouLuron I. Dietary protein excess during neonatal life alters colonic microbiota and mucosal response to inflammatory mediators later in life in female pigs. J Nutr. (2013) 143:1225-32. doi: 10.3945/jn.113.175828

162. Bansal T, Alaniz RC, Wood TK, Jayaraman A. The bacterial signal indole increases epithelial-cell tight-junction resistance and attenuates indicators of inflammation. Proc Natl Acad Sci USA. (2010) 107:22833. doi: 10.1073/pnas.0906112107

163. Hughes R, Kurth MJ, McGilligan V, McGlynn H, Rowland I. Effect of colonic bacterial metabolites on Caco-2 cell paracellular permeability in vitro. Nutr Cancer. (2008) 60:259-66. doi: 10.1080/01635580701649644 
164. Gao J, Xu K, Liu H, Liu G, Bai M, Peng C, et al. Impact of the gut microbiota on intestinal immunity mediated by tryptophan metabolism. Front Cell Infect Microbiol. (2018) 8:13. doi: 10.3389/fcimb.2018.00013

Conflict of Interest: The authors declare that the research was conducted in the absence of any commercial or financial relationships that could be construed as a potential conflict of interest.
Copyright (C) 2021 Chalvon-Demersay, Luise, Le Floc'h, Tesseraud, Lambert, Bosi, Trevisi, Beaumont and Corrent. This is an open-access article distributed under the terms of the Creative Commons Attribution License (CC BY). The use, distribution or reproduction in other forums is permitted, provided the original author(s) and the copyright owner(s) are credited and that the original publication in this journal is cited, in accordance with accepted academic practice. No use, distribution or reproduction is permitted which does not comply with these terms. 